\title{
Globalización, hegemonías y medios de comunicación: El Mundial de Brasil y el fin del "juego bonito"
}

\section{Globalization, hegemonies and media: The World Cup in Brazil and the end of the "jogo bonito"}

\author{
Juan Pablo Zebadúa Carbonell' \\ Universidad Autónoma de Chiapas, México
}

\begin{abstract}
Resumen
Esta entrega resalta la justa mundialista pasada, realizada en Brasil, como un espacio deportivo mundial, donde se pudieron observar distintos vectores culturales por donde se catalizan procesos culturales emergentes. El Mundial de Fútbol de Brasil 2014 pasó de ser un evento futbolístico per se a uno donde los medios de comunicación masiva generaron distintos discursos que van desde las apuestas de mercantilización de un deporte de alta competición, hasta la generación de alta tecnología dispuesta para construir arquetipos mediáticos en los jugadores y en el fútbol en general.

Priorizando lo anterior, el "juego bonito", como metáfora de las habilidades y desarrollo del juego como parte del espíritu nacionalista brasilero que imperaba en estas justas, ha dejado de ser importante para dar paso a la generación cyber de jugadores, donde la tecnología, el poder corporal y la potencia son factores que rebasan la habilidad y el jogo bonito.
\end{abstract}

Palabras clave: globalización, fútbol, medios de comunicación, hegemonía.

\begin{abstract}
This document highlights the last World Cup, realiced in Brazil, as a global sport, which shows us different cultural vectors where emerging cultural processes are catalyzed. In the World Cup Brazil 2014, that was a futbolistic event per se, it becomes a context where mass media generated different discourses ranging from bets of commodification in high-level sport, to the generation of high-tech ready to build archetypes media players and football in general.

Then, the "jogo bonito", as a metaphor of skills and game development as part of the brazilian nationalist spirit that prevailed in these games, is no longer important, because it make a way for the generation of "cyber" players. Here, the technology, the body power and strength are factors that are beyond the ability and the jogo bonito.
\end{abstract}

Keywords: globalization, football, media, hegemony.

1 Antropólogo social con Doctorado en Antropología y Estudios Interculturales por la Universidad de Granada, España. Es profesor investigador de la Universidad Autónoma de Chiapas (UNACH), México. Pertenece al grupo de investigación Deporte, globalización y cultura de la Facultad de Humanidades de la UNACH. Email: jpcarboney@gmail.com 
Contra muchas de las expectativas el Mundial de Brasil 2014 resultó ser un evento con mucha carga emotiva. Intenso, dramático, lleno de vértigoy, en algunos casos, dotado del particular escándalo que llevan consigo las pasiones en los deportes de alta competencia. No obstante, a lo largo del Mundial una apuesta perduró siempre en la penumbra de esta FIFA que se niega a sobresalir como una institución de vanguardia y que, por el contrario, se observa anquilosada aún a costa de la propia historia que le exige sea más precursora de los elevados valores con que se activa, en el discurso, en el ámbito mundializado. Porque, en el fondo, cualquier actividad que se desarrolle de esta manera, internacionalizada y masificada, debe tener en común la defensa a ultranza de la equidad y de la moral deportiva. Quizá sean adjetivaciones superfluas a estas alturas de la mediatización internacional, pero es lo que realmente debe prevalecer en los acontecimientos de esta talla $y$, en ese sentido, aun la FIFA la tiene muy difícil para escapar de dicha coyuntura globalizada:

La globalización, anunciada como un fenómeno nuevo, busca ponerle el último clavo al ataúd de cualquier posible orden mundial distinto. Tiene por función ideológica la de mistificar lo que está ocurriendo[...] El mensaje de la globalización es que el mundo de hoy es como es, y que es preciso tomar ciertas medidas como resultado. Básicamente, es preciso que los estados muestren su aquiescencia con los requisitos del mercado global (Cole, 2007: 159).

En todo caso, si la ética y la moral aún no se perciben en la FIFA en su totalidad, por lo menos en el despliegue del juego futbolero sí se pudo apreciar. Esta doble condición, muy ausente en los últimos mundiales, tuvo su epílogo en el juego de la final: digno de una Copa del Mundo, con mucho el mejor juego de todo el torneo. Durezas al margen, la honorabilidad se manifestó en el buen fútbol que desplegaron Argentina y Alemania; el primero, fuerza y pasión durante todo el encuentro; y el segundo, colectividad y técnica.
Se cuenta que el general inglés, Bernard Law Montgomery, en la Segunda Guerra Mundial y en la campaña del norte de África, tenía una fotografía en su escritorio de Erwin Rommel, el legendario Zorro del Desierto alemán. La foto era el recuerdo constante de lo que Montgomery llegó a hacer en África: sacar al Mariscal germano y derrotarlo. Montgomery idolatraba a Rommel, al mismo tiempo que era su rival acérrimo; su alter ego en una cotidiana y constante dialéctica vital. Precisión y eficiencia era lo que tenía que superar. Al final Rommel se fue, pero no derrotado. $Y$ tampoco el inglés lo superó en estrategia.

Así fue el juego de la final. Argentina, en el mejor partido que haya jugado en todo el Mundial y en prácticamente todo el proceso mundialista de cuatro años atrás, simplemente no podía hacer más. Hizo el mejor esfuerzo, pero era lo que más debía y alcanzaba a desarrollar. Y al final, Alemania, como siempre, como debe ser, como si la historia del balompié ya estuviese escrita, sacó esa cosa (¿genética?) que nadie entiende ni explica, pero que para todo es una inmensa realidad: eficacia.

Ni Mascherano, incansable y extraordinariamente gigante en el campo, pudo con el paquete. Porque se necesitan más que simples deseos y ganas de vencer al émulo moderno de la wehrmacht. En el fútbol alemán de lo que se trata es de construir un sistema con la dinámica de todo un pensamiento y orden racional que según esta lógica necesita el mundo. De ahora en adelante así serán las cosas en el nuevo orden teutón.

Desdeesta perspectiva, dos grandes conclusiones emanan del Mundial Brasil 2014. Por un lado, la nueva hegemonía teutona y un nuevo tipo de juego que se apresta a llegar a ser mundializado y pone fin a la era del "juego bonito" que llevó al Barcelona de "Pep" Guardiola a convertirse en el mejor club de todos los tiempos y llevó también a la selección de España a un campeonato del mundo (2010) y dos Eurocopas (2008 y 2012), logro que ninguna selección nacional había logrado. 
La hegemonía del "juego bonito" consistió en reconvertir el fútbol contemporáneo a su raíz primigenia, que era el ponderar la calidad y la estética del juego de frente al resultado por sí mismo. Ambas características fueron entronizadas y puestas en marcha como tradición y escuela futbolística en el Brasil histórico y legendario precisamente por ese tipo de fútbol, y llevadas a su clímax con la oncena de Pelé en campeonato del mundo de 1970.

Si en estos tiempos, hablando de diez años para atrás, la tendencia internacional era la incipiente estrategia del trazo duro y calculador en el esquema táctico, con más presencia en una sólida defensa y fuerza explosiva en el ataque, el "juego bonito" del Barcelona rompe tal esquema, poniendo una trinchera de tocadores de balón que entre sus más denotadas características era la inteligencia por la amplitud del campo de juego y el gambeteo a ultranza: es decir, la vocación del diez tocador y pensante por encima de la verticalidad. Para ello, Guardiola recluta a jugadores sin el físico requerido para el fútbol europeo; a cambio, los deja jugar. ¡Y tocar! El resultado es ya legendario: después del Brasil 70 , nunca se ha visto tal vistosidad, seducción y belleza en el fútbol.

No obstante, toda hegemonía tiene su fin, dicen los historiadores. Las hegemonías, como concepto sociológico de gran importancia analítica (Szurmuk y McKee, 2009), sirve para recordarnos que no debemos esperar que la cosa dure mil años. ¿Consuelo de tontos y desvalidos? No hay tal cosa. Lo que sí hay certeza es que, si cualquier horizonte que se presta a generar y construir historia, y parte de la idea de que "lucha" contraculturalmente de frente a un establishment y un orden dado, cuando llega al sitio de lo que niega y permanece así, imbatible e incólume, con el tiempo conforma ese espacio hegemónico, y eso puede representar confort y pereza.

Quizá eso pasó con el Barcelona. Desde hace un poco más de un año se decreta el fin de la era del Barça, es decir, de esta generación que hizo posible al club más grande de toda la historia. $Y$ se resalta no porque no sigan haciendo las cosas que les dieron realce y palmarés en este proceso ya casi secularizado de la oncena de Guardiola, sino porque, siendo un equipo de tal envergadura, perder es una palabra que no entra en el vocabulario de los catalanes. Aun así, han dejado ir los últimos campeonatos de los que habitualmente se acostumbra a que sean exclusividad del club. ¿Qué ha pasado? ¿Los días del futuro pasado ya llegaron? ¿O es el fin del ciclo ya antes cantado por los críticos de las hegemonías, es decir, una obvia culminación de un estado de cosas que tiene que terminar?

Aquí unos primeros acercamientos que tratan de contestar tal interrogante. Que nadie tenga duda de que al ser el gran equipo $y$, sobre todo, la gran estrategia a vencer, el Barcelona se convirtió en referencia para los ajustes necesarios "y decididamente rápidos en términos de los tiempos futbolísticos" que todos los equipos del orbe realizaron para anular toda proeza del "juego bonito" que enarboló el Barça a lo largo de cinco años. En ese sentido, el contexto de los ajustes se dan porque el "Brasil de Europa" ha perdido brillo y con ello se va una generación irrepetible que, quizá, nunca podremos ver en todo el espectáculo de ganar y jugar bien; de tocar el balón sin menoscabo de la contundencia necesaria para ganar, siempre ganar.

La historia ya se proclama como leyenda. Josep Guardiola, un canterano del Barça, sin más curriculum que haber sido entrenador del segundo equipo del club culé, y sin más aureola que su innato olfato para un planteamiento táctico que remite al verdadero fútbol "aquel que ya se había perdido en aras de los mercados y los triunfos a ultranza, es decir, anteponer el "juego bonito" por encima de cualquier objetivo que estuviese sobre de la cancha", se convirtió en el entrenador más ganador de todos los tiempos y creó al trabuco más contundente que jamás se había visto en los céspedes internacionales. De la mano de los "comandantes" más finos de la media cancha en los últimos años, Xavi e Iniesta, y de ese fenómeno incomparable Ilamado Lionel 
Messi, el Barça se convirtió en referencia, en un horizonte a alcanzar, en primer lugar; y poco después a contener. Fue una forma de entender el fútbol como parte de la condición humana desde la "estética" y con la carga de dignificación que eso conlleva:

Cuando se habla de fútbol, hay queentenderlo en su sentido básico como todo juego y/o deporte que se desarrolla en torno al eje balón-pie[... ] sin embargo, una vez establecida la archiconocida lógica formal de fútbol, aparece otro problema: el de la distinción de las diversas estructuras que concurren y los ámbitos simbólicos que coexisten, unas veces superponiéndose y otras veces (con) fundiéndose, de manera especial en las dimensiones simbólicas y de significados. Porque la pelota de fútbol, tan pronto es un juguete como el "objeto" en torno al cual gira una profesión y un negocio. $Y$ esto mismo ocurre con el "fútbol" y con el "deporte", que pueden vehicular las ideas más insospechadas o los intereses y negocios más sorprendentes. Por constataciones como éstas, es decir, ante el poliformismo, la multidimensionalidad y el carácter polisémico de toda estructura cultural, socialy deportiva, cualquier investigación (desde el fútbol) debe asegurarse que ha profundizado lo suficiente para alcanzar interpretaciones y conclusiones realmente explicativas de la acción humana (Alonso 2012: 65).

Ante la fuerza física estaba la destreza con el dribling y la mente sagaz que organiza el campo mucho antes de ser visualizado. Ese Barça, en promedio, no medía más allá de los 1,75 centímetros, y el "juego bonito" desplegado rindió incluso a los más fanfarrones de este juego, y creó toda una escuela que quedará marcada para la posteridad.

Pero los ajustes llegaron rápido. Prácticamente todo equipo de alto nivel competitivo comenzó a ver la necesidad de contrarrestar tal funcionamiento colectivo. De esta forma, a manera de contraste y posicionamiento de una estrategia distinta para invalidar el "tiqui-taca" surge en el mundo del fútbol la presencia de la biomecánica como recurso técnico para generar los físicos requeridos para tal fin, casi en la metáfora de hechuras de cuerpos de laboratorios para ganar potencia y fuerza en el fútbol internacional: de frente a jugadores pequeños, rápidos y expertos en el toque fino y el dribling, se encontraban otros jugadores potentes, verticales y fuertes. Fuerza física. Así, Mario Balotelli, Cristiano Ronaldo, Zlatan Ibrahimović son de los jugadores más representativos de la generación cyborg del fútbol. Fuerza y contundencia fue la consigna.

En ese sentido, la gran fuerza de los transnacionalismos también formó parte de esta condición. La apuesta de estos jugadores que ahora irrumpen los campos de juego del mundo no tiene que ver con los amores a las camisetas nacionales. Por el contrario, ya no se privilegian las pertenencias "de origen", sino lo que pueden generar ya en los mercados globalizados, independientemente de qué equipo sea por el que se juega:

El transnacionalismo tiene fronteras $y$ similitudes con temáticas tales como globalización, sistema mundial y división internacional del trabajo. Sin embargo, su propia distinción radica en el hecho de que la transnacionalidad apunta a una cuestión central: la relación entre territorio y diferentes arreglos simbólicos y políticos que orientan las maneras en que las personas representan su pertenencia a unidades sociopolíticas y económicas (Lins Ribeiro, 2003: 61-62).

Por ejemplo, si nos atenemos a la lógica vista en el Mundial, todos los jugadores llegaron muy cansados y bastante desbalanceados desde el punto de vista físico. Ahí tenemos a Cristiano Ronaldo, a Modric, a Di María y al mismo Messi; nadie estuvo en su nivel adecuado para jugar una copa del mundo. Y es que nadie, en el sano juicio capitalista, le apuesta a ganar por la "camiseta nacional" porque de por medio están sus contratos multimillonarios que deben de cuidar para sus carreras profesionales. Así, el Mundial ya no es un escaparate internacional donde se dirimen las fuerzas "nacionales" en 
turno. El color de los "países" (sí, con comillas y con todas las dudas posibles del término) nunca ha sido más dejado de lado, y más marginado que nunca. ¿Qué tan portugués es Cristiano? No se sabe. ¿Se sentirá más cerca de su "patria" que cualquier otro luso? Tampoco es certeza. Con las ingentes ganancias monetarias que genera su figura no necesita país.

Son los mercados, los grandes flujos del capital global lo que impera ahora (Fernández, 2010). En ese sentido, no importa el buen juego, tampoco los "héroes nacionales" de antaño, sino los deportistas asépticos, fríos y calculadores desde el punto de vista de lo que impactan en términos capitalistas.

Y en esta ecuación los medios de comunicación como punta de lanza para la expansión de esta idea. En efecto, las Ilamadas "tecnologías de la información" estructuran gran parte de la cotidianidad del mundo, por tener influencia en cualquier ámbito de la vida de las personas. La telefonía celular, la televisión por cable o el Internet son ejemplos de la gran variedad tecnológica por la que se mueve el planeta a partir de una complejísima interacción del sistema de las comunicaciones. Los medios de comunicación, como productores de mensajes, hacen uso de esta tecnología y se lanzan por todos los rincones del orbe, con tal capacidad e influencia que se observa ahora el nacimiento de una "tecnocultura", una alianza estratégica entre los medios de comunicación, la tecnología y la economía de mercado, como característica de los tiempos que vivimos: por supuesto, también desde las poderosas industrias culturales (Pereira, Villadiego y Gutiérrez, 2008):

Mediatización es el nombre que ha recibido el proceso de articulación del funcionamiento de las instituciones sociales con los medios de comunicación. En la sociedad mediatizada, la tecnocultura es una designación, entre otras posibles, para el campo comunicacional como instancia de producción de bienes simbólicos o culturales, pero también para la impregnación del orden social por los dispositivos maquínicos de estetización o culturalización de la sociedad (Sodré, 2002: 9).

La antepasada temporada el Barça no se llevó ningún trofeo. Muchos de sus grandes jugadores pasarán a retiro y se desmantelará el mejor once de toda la historia de los clubes. No se vislumbra un cambio de timón en cuanto a estilo de juego, pero no son ellos quienes deben de pensarlo ni preocuparse. El Barça, simplemente, seguirá alimentando su propio mito hasta que llegue el relevo generacional y, con ello, la inmortalidad de esa época gloriosa que, tal vez, nunca se repita.

Una consecuencia inmediata del nuevo esquema de juego alemán es el ya difundido como el fin del "juego bonito". Los últimos héroes del toque se están yendo y con ello la última de las etapas más vistosas de este fútbol que desde que apareció situó como principal argumento la diversión a toda costa, y evitar esa ceguera que incomunica, hasta el fastidio, la idealización del buen juego ante la visión utilitaria del triunfo a toda costa. Incluso a dispendio de matar el fútbol.

\section{Referencias}

Alonso Meneses, G. (2012). "Heteroestructuras culturales e identidad al interior de un club de fútbol de inmigrantes gallegos en Barcelona", en Guillermo Alonso Meneses y Luis Escala Rabadán, Offside/Fuera de lugar. Fútbol y migraciones en el mundo contemporáneo, México. Colef, 2012, pp. 63-85.

Cole, M. (2007). "La 'inevitabilidad del capital globalizado'. Contra la prueba de 'indeterminabilidad': una crítica marxista", en Luis Huerta-Charles y Marc Pruyn, De la pedagogía crítica a la pedagogía de la revolución. Ensayos para comprender a Peter MacLaren, México: Siglo XXI, pp. 159187.

Fernández, E. (2010). Comunicación, cultura y poder en la sociedad de la información, México: UACH. 
Lins Ribeiro, G. (2003). Postimperialismo. Cultura y política en el mundo contemporáneo, Argentina: Gedisa.

Pereira González, J.; Villadiego Prins, M.; Sierra Gutiérrez, L. (coords.) (2008). Industrias culturales, músicas e identidades. Una mirada a las interdependencias entre medios de comunicación, sociedad y cultura, Bogotá. Universidad Javeriana.
Sodré, M. (2002). Reinventando la cultura. La comunicación y sus productos. Barcelona: Gedisa.

Szurmuk, M.; McKee, R. (2009). Diccionario de estudios culturales latinoamericanos, México: Siglo XXI. 